\title{
COIMBRA... PIEDRA Y PAISAJE
}

(Poemas)

\author{
Guillermo de la Cruz-Coronado \\ Universidade do Paraná
}

En 1951 el "Curso Internacional de Férias" de la Facultad de Letras de la Universidad de Coimbra editó por primera vez estos poemas compuestos en el curso del año anterior. Esa primera edición, de la que se hizo una tirada especial de lujo con ejemplares numerados y rubricados por el autor, se ha agotado hace tiempo. Al reeditarlos ahora en "Letras" deseo satisfacer a tantos enamorados de la célebre ciudad universitaria que me los han pedido. A ellos se los entrego. Pero quiero al mismo tiempo que esta nueva im. presión en la capital paranaense y en la revista oficial de su facultad de Filosofía sea el testimonio de mi afecto al mundo luso-brasileño simbolizado en sus dos ciudades universitarias, de aquende $y$ de allende a las que como poeta y como estudioso de la poesía me siento tan estrechamente vinculado.

La más notable diferencia con la edición anterior consiste en haber prescindido de la división en partes, y haber, por tanto, dado los poemas en numeración corrida, más apropriada al espiritu de una revista. Esta numeración sigue el orden de la primera edición atendiendo al contenido y no a la cronologia de los poemas. He eliminado las dedicatorias y demás ornamentos. \\ ORACION ENTRANDO EN LA CIUDAD}

No abrases esta tierra, Señor; mata tu ira en mi.

Déjala intacta, tierra casi sin pecado, casi como cuando tú la creaste, puramente dulce, puramente verde, blanca, rosa, puramente palabra tuya fuera... 
todavía integra,

todavia tierna,

todavía enamorada de la altura,

contenta de su pequeñez de creatura...

He llegado donde mi corazón presentía una hartura de seres primigenios...

mi corazón tiene un aturdimiento de verdad nativa como cuando el primer paisaje del mundo fué luz exacta y abierta para los ojos blandos de Adán.

Este paisaje reblandece mis ojos, gotea sobre mi corazón, y casi me siento como con la primera carne, la que tú sacaste del manantial de los lirios, de la voz humana del pájaro y de la palabra divina del hombre...

la palabra humana antes que el pecado la obligasse a salvarse en el barullo de lo que no te quiso $\checkmark$ luego te buscaba angustiosamente ordenando su fealdad...

Aquí todo tiene el desorden de lo que es bello por todas partes $y$ no cuida de ser imagen de ave, de flor, de monte, de arquitectura humana o de metal nítido...

todo seguro de ser bellamente algo, bellamente valle, árbol, rio, piedra cristalizada en hueso de humanidad. . .

Ay, Señor, no abrases esta tierra, o. . ciega a mi vida este momento y engaña piadosamente mi mañana. 


\section{CANTO INICIAL A TODA LA PIEDRA}

Canto a la piedra... la piedra sin ojos que llora una lágrima poligeométrica secularmente más grande... que nunca en la mejilla rueda; la piedra que sabe llorar y nunca se deshace en pena.

Canto a la piedra, cuerpo horizontal, dormida, muerta en el murn, quieta, sin forma animica, pura piedra.

Canto a la piedra vertical, despierta, que esboza en rostros medievales su sonrisa eginética... y toma aire $y$ aletea en un vuelo de paños, imposible porque el tiempo le pesa.

Canto a la piedra religiosa, tensa, que en la columna se alarga $y$ en el arco se arranca de la tierra.

Canto a la piedra que conoce el mar, marinera, maroma de navío, mástil de carabela en la portada manuelina con nostalgia de mareas, de aguas bravas, de aves altas, 
de recio sabor de sal y pesca;

piedra navegante con cara a otro mundo

para el éxtasis y para la empresa.

Canto a la piedra sin dimensión precisa, piedra que piensa

que contiene todos los volúmenes, que ya casi no es piedra.

Canto a la piedra sepulta

que alimenta otras primaveras, lentamente consumida en la entraña chupada por la erguida piedra nueva.

Rostro de la ciudad, hueso de la tierra, cuerpo y configuración de espíritu... piedra de Coimbra, piedra...

Coimbra, 18-VII-1950.

111

\section{PIEDRA UNIVERSITARIA}

디 hierro se hizo nervio, fué idea la espada, voz que rebotó en muchas piedras creándoles la figura y el alma.

El tiempo se encarnaba diferente en una pedrería extraña desde el alcázar primero sobre la loma calva... contenida y difusa, redonda y esquinada. 
humanizada y bruta, sepulta y alta...

con calor de carne amanecida, con dolor de tiempo y lágrimas, lamida a besos de tantos vientos con labios que bruñen y descarnan.

Universal, piedra universitaria, mito encarnado en cerebro dulce, Palas, pensamiento erigido, palo de lanza...

Torre, verga mayor: caudal de palabras endurecido en el aire hacia la fuente de las aguas...

la ciudad desde todos los ángulos tiene su sentido para mirarla, se sumerge en ella, reclama su sangre y su cara.

Piedra de todo el hombre, claustro de su sustancia, concreción de su andadura, de su vecindad en la noche, de su lejanía en el alba...

Piedra de todo el ser, vegetal y heráldica, de las plumas del ave, de la partitura increada...

Medieval, manuelina, barroca, pombaliana... 
y algo también sin piedra:

ática.

\author{
Universal, \\ universitaria, \\ oración del cerebro, \\ pensamiento del ansia... \\ materia para todas las formas... \\ palabra, palabra, palabra. \\ Coimbra, 31-VII-1950.
}

IV

\title{
SE VELHA
}

Piedra noble, apagada, sin voz para el aire, toda idea, toda vibración antigua, toda firmeza.

Piedra maciza, cuadrada en la raíz donde la fe comienza, arqueada en redondo, arco perfecto, brazos para la unidad perfecta.

Fuera... cuánto desprecio al día, cuánta aristada ausencia, cuánto deseo de nubes pululándote en almenas...

atemporal, decididamente clavada frente al agua $y$ al sol que ruedan... cuajada en tiempo sin alas, volumen sin quiebra.

Dentro. . cuánto parpadeo invisible en las galerias secretas, 
cuánto ojo profundo

de la arquería ciega

toma la luz todavía más de dentro,

de ráfagas que germinan en madera

acariciada de oro y polvo bienoliente...

madera ascensional

aliento de la vecina, blanca, ennegrecida, equilibrada, transfigurada piedra.

Aquí estuvo Rodrigo con coraza de acero, con el pulso reventándcle las venas, con sus ojos para la llanura y su corazón con un relincho para el beso y la espuela...

El buen Cid castellano vino un día caballero sobre Babieca, dijo unas palabras devotas, besó una cruz de espada y salió fuera...

toda la eternidad de la roca labrada se hizo brillo en la punta de su espada nueva.

"Sé Velha"...

mirando para Castilla

se te encendieron las piedras

en los ojos del caballero entre el polvo de la llanura sangrienta...

quedaste definitiva, estática como una llama alerta toda comunión universal y olor de fuego por dentro, toda perfil de arista por defuera.

Ella misma se cerró de ojos, entregó a la pura fe y esperanza sus piedras. 


\section{V}

\section{CLAUSTRO DO SILENCIO}

Silenciosamente labrado

en el claustro interior de un "mestre" poeta que gustaba de transformaciones súbitas $y$ de macizo son de piedra...

Milagro reciente de arquitectura nueva que sacaba árboles y jarcias arboladas golpeando la roca muerta.

Era una masa obscura, desperdigada, antes de la voz milagrera; tenía los huesos aplastados en la angustia de la tierra.

Una voz de ángel vino... $y$ el aire trajo una riada soplada por el cauce del poeta...

El hilo de palabras, dúctil como una hebra, crecía como un vástago, se retorcía como una mimbre tierna, llameaba en arcadas, olía en flor de piedra.

Luego. . seguía siendo voz arrancada al silencio de la tierra, sombra que salía de la palabra... materia.

No tenía corazón y se lo daba al hombre, corazón sin carne y sin madera, corazón de sangre que fluía no sé de qué recónditas venas... 
Fué cada vez más forma, cada vez más la voz del ángel primera, cada vez más hombre, más tiempo, muchas esencias en su esencia.

En su ascensión de ser - piedra, alma, figura angélica se le arrugó la piel, desfalleció la madera...

Un ala que voló cuatro siglos, de ida y de vuelta, lo consumió con besos de plumas...

Volaron los pétalos de las arandelas, $y$ polen $y$ perfume fueron polvo y olor de cera.

Pero algo estremecidamente igual — ser de tiempo, tránsito y permanencia - . .

algo indefinidamente todo

— ángel, hombre, materia - ...

algo sigue siendo siempre...

silencio, palabra de la piedra.

Coimbra, 26-VII-1950.

\author{
VI \\ PAISAJE TOTAL \\ (Desde la torre de la Universidad)
}

Pequeña luz asomada a los valles que la pereza del día intimida;... 
valles más allá del "Penedo",

lecho de la llama difusa

que desganadamente baja

perfilando las colinas como una margen que se enciende.

despertando el color de los pinos lejanos, de los árboles que todavia no tienen nombre.

Bruma... sola una nube

con un rasgón indeciso en Oriente

mordido por la alegría inicial de los montes...

paisaje de nubes que fatiga los párpados, repliega avaramente sus límites

contra la amorosa distensión de los ojos.

El día está aquí mismo

sobre la lámpara de la torre;

de mi se difunde una mortecina claridad

que me coloca en el centro de la luz.

Llega a media mañana

el sol, primeros labios, donde el agua duerme, a los tejados más altos,

al verde ribereño lleno de deseos del día, a la chopera animada de franjas instantáneas.

El río arrastra un sueño sosegado impasible a las caricias del fuego;

una diminuta arteria a flor, casi no circula, sangre recién muerta...

pero la arena se mueve siguiéndose a sí misma penosamente, curvadamente como un arco relajado sin flecha y sin dos brazos gigantes.

Ahora el sol pinta de verdad el paisaje, blanco, verde, tierra, colorado... 
abajo está la piedra

- yo soy una piedra móvil en lo más alto, cabeza de toda la piedra hermanada, aglomerada; se mira a si misma, se habla, concentra la vida que se le entrega,

sube alegre las colinas, se alarga a las ondonadas, brota en todas las laderas medida de los pliegues innúmeros, pródiga de su mate regocijado...

casas hileradas, bosques creados por el hombre, bosques rojo y blanco donde su corazón florece en miembros blancos y asombros infantiles.

Geología replegada en colinas redondas, verde claro y grisáceo, pliegues que se montan y suceden ilimitadamente, relieve manso en el valle grande descansando la cabeza del rio... piel geológica a que aflora en paisaje total, vario, idéntico - árboles, árboles, árboles el pulso latente de la ciudad que no muere.

Coimbra, 27-VII-1950.

\section{VII}

\section{PENEDO DA SAUDADE}

La tierra es una tristeza recogida donde la dimensión se pierde por unos cauce grises; más allá de los límites del ojo 
unas sombras que caen desde el cielo

casi no llegan a la tierra,

casi le dan un beso levísimo...

y los cabezos, testas humanas,

se multiplican

como un cabello que se alarga

y se ondula infinitamente.

El valle tiene una luz incierta;

sólo los olivos cercanos,

las pitas y unas cuantas cosas

lo son de verdad para mis ojos.

Pero yo no los miro, los siento

en la oleada y el rumor de la savia y la sangre

cuyo golpe hinche y aproxima los vasos y las venas...

No los miro con las pupilas dilatadas

hacia líneas lejanas,

nubes envueltas en piel de otras nubes, pie que huye del calor de la mañana en la tierra, piel incolora desgarrada por el sol tardío.

Pero a veces através de su ojo grande que clava su luz sobre los árboles. sobre la plata obscura de los olivos. sobre las plantas amarillas, violeta, rosa claro del camino que zigzaguea $v$ se contradice (arteria del "Penedo" que le alimenta de sangre humana, de voces humanas...)

a través de su llama contra las nubes.

a veces el valle es súbitamente diáfario,

o el último repliegue pierde lejanía,

- la sangre apagada de los tejados grita,

- las pitas acero vibran su manojo de espadas.

Sólo unos rectángulos en el fondo, unos manchones de brocha gorda en los declives, 
apegados a la tierra,

mantienen el secreto de su esmeralda continuo...

y el agua de la piscina se mueve siempre

hervida por la carne desnuda del hombre.

Coimbra, 16-VII-1950.

\section{VIII \\ PENEDO DA MEDITAÇÃO}

Corazón donde la ciudad se refugia...

corazón donde canta

el gozo vegetal de las cañaveras y el viento...

corazón solitario

en que es mucho más grande el músculo que la sangre.

El sol valiente de esta tarde

ha irritado todos los colores,

ha gritado a toda la savia

hasta el borde mismo donde el labio se entrega...

brisas orquestrales

a las que el ruiseñor impone el silencio un instante...

cielo, cielo.

Coimbra tiene aquí su cuerpo resucitado

dentro de su propio corazón...

ondulado, abismal, verde, acerado,

largo como el regazo del hondo,

herido y sangriento,

lágrimas bermejas de los arándanos...

olivos y pinos nostálgicos,

sombras tardias de las laderas, 
sol exaltando las cimas,

proximidad del agua casi ausente...

lejanías de montes, de árboles, de cielo...

"algo" por donde pueda escaparse "todo"...

algo que no sea más que eso:

lejanía, lejanía...

ciudad que huye de sí,

ciudad que no se encuentra,

que no quiere.

$Y$ sin embargo ciudad íntima,

ciudad encerrada en la pequeña cavidad de un pedazo de carne, toda recogida en la sal de una lágrima, cuyo latido llega hasta nuestras arterias. se suma a nuestro pulso, lo enrojece...

ciudad entrañable, que se pierde de sí y se encuentra en nosotros...

paisaje todo ciudad, todo su alma, todo alma nuestra.

Coimbra se abre sola, se da amorosamente, a los ojos, a la adoración, al habla...

pero se guarda siempre intangible al abrazo y a los labios...

la realidad asusta su sueño y le atormenta las piedras...

ella reposa en nuestro hondón más vivo donde no entran más que la oración sin brazos y la sangre que con ella se pierde en el mismo sueño. 
Dejadla así los que la amáis:

no persigáis su cuerpo.

bello desnudo, nocturno, inaccesible, con que la luna huye en el fondo del río.

Coimbra, 3-VIII-1950.

IX

DOLOR DE ANTIGUEDAD

(Oración final)

Destruye al que desgarra esta ciudad, Señor,

al que no sabe del dolor humano de la piedra, del horror de la belleza nueva

que grita su triunfo contra el oro antiguo.

Aplasta a los filisteos

que ignoran la belleza metálica del arpa

que no tiene sonidos

pero que hace vibrar el corazón del hombre;

que ignoran la belleza del arco sin luz

pero que la enciende en los ojos puros;

que ignoran que el espiritu sobrevive

sobre las ruinas del tiempo que es también espíritu;

que ignoran que el espíritu anda por calles difíciles pero que suben siempre.

Señor;

aniquila al que mata el espíritu

de esta ciudad, milagro antiguo. contra el que no se atrevió el tiempo pasado.

Coimbra, 12-VII-1950. 


\section{TRIÂNGULO LIRICO}

\section{A \\ TRIPTICO DA AGUA \\ Elias Leite C. .. F. São Paulo \\ 1}

MEU BARCO A VELA

Meu barco à vela, rio acima,

lento.

Irmão das águas.

Irmão do vento .

Meu barco à vela.

Meu pensamento.

Águas tranquilas, margens lodosas, sombras compridas, rosais e rosas:

florescimento.

Saudade à tona.

Meu barco à vela, que bom!

tão lento...

Vem, garça branca!

Meu pensamento. 


\title{
CANTO Ȧ ONDA MORTA
}

\author{
Perdi o sentido \\ do mar distante. \\ Fui navegante. \\ Cortei o mar. \\ Achei a espuma \\ de uma onda fria \\ que o mar perdia \\ sem se importar.
}

Guardei a espuma, chorei a onda morta na praia. Culpa do mar.

Minha jangada. Minha vela panda. Meu sonho infindo no mar dormindo.

Restos na areia... Vou me culpar.

NAVEGANTE

Lá no mar alto em sinfonias de côres, galopam nas ondas irisadas espumas.

Lá no mar alto, um sendal de rumores vem em busca da praia, nas manhãs sem brumas. 
Lá no mar alto

há um céu tão perto, que os mastros dum barco

o tocariam, por certo.

Lá no mar alto,

o meu mar de sonhos, bracejo com as ondas, me molho de aromas, me envolvo nas algas que enlaçam meu barco com amplexos medonhos.

$\mathrm{E}$, barqueiro volúvel, no mar inconstante, sem rumo certo, viso o Porto-Esperança que está tão perto...

\section{B TRIPTICO DA ANGÚSTIA \\ Yrelise Araújo \\ Paraná \\ 1}

MINHA NOITE

Quem é capaz de me devolver minha noite estrelada?

Minha noite estrelada do tempo de criança!

Onde estás, minha noite?

Onde está o fulgor das tuas estrêlas distantes?

Tenho te procurado em vão mas não desisto!

Minha noite. . Eras tão bela, tão pura, que nem parecias noite! Eu gostava de sentir o teu hálito gelado.

$\mathbf{E}$ eu tinha medo de ti quando minha bábá me dizia: "estamos na boca da noite" 
Então eu imaginava coisas tenebrosas...

Mas agora nem ao menos medo eu tenho!

Penetro-te todinha, acordada e sem sonhos.

E tu agora és tão noite!

Quem foi que bafejou o espelho do céu para que eu não pudesse ver as estrêlas?

Se eu descobrir quem foi, mando a boca da noite engulí-lo!

Isso não se faz! Eu quero o brilho gelado das estrêlas!

Ele me faz bem.

Minha noite estrelada do tempo de criança, Ó ciranda, cirandinha.

$\mathrm{Eu}$ te acharei!

Claro que te acharei, pois deves estar dentro de mim, bem escondida no meu coração.

\section{2}

\section{NEBLINA}

Visões que se esboçam indecisas... será sonho?

Indecisas como luzes de velas... Existirão?

E doce velar assim junto delas,

delas que se movem, que vêm, que vão, vagamente...

Vagamente que nem as ondas do mar... e as estrêlas?

Onde seu brilho azulado?

E a neblina difusa escondendo, ocultando..

Ocultando o que?

Os sonhos e as estrêlas?

Vagamente visões indecisas...

Vagamente no meu coração... 


\section{CAOS}

Mãos estendidas e vazias, órbitas vazias de luz

Tateando, procurando em vão...

Tateando, procurando o infinito intangível.

Mãos perdidas, mãos aflitas que não encontram outras mãos . Sol que tortura a alma saciada de neblina.

Angústia infinita pairando no ar.

Até quando essa neblina sufocante que côa a angústia?

Mãos perdidas, mãos sozinhas desprovidas de anéis

Ligai-vos, estendei-vos, o sol rasga a neblina;

ligai-vos, estendei-vos, detrui o caos!

Reparai, olhos murchos, há sol!

Contemplai vossas mãos, estão orvalhadas orvalhadas de lágrimas de amor.

\section{$C$ \\ TRTPTICO DE AMOR}

\section{Amilcar Oralde \\ Buenos Lires}

1

DE TODO ROSTRO...

a C.

De todo rostro vuelvo desolado, con sensaciones de caídas, defraudado

de lo humano todo; 
porque detrás de esas imágenes pintadas está tu rostro único, el que sostiene y salva este sentido místico de vida, que es mi existencia de amor en amor dada y padecida.

Vivo en ti, y en ti vuelvo a proclamar mi sino de hombre trascendido, de ángel recuperado; tengo la misión alta de custodiar tu cáliz, donde recibo y guardo el único testimonio de amor dado en gracia de vida, $y$ en fe de salvación eterna.

Por eso me hallarás, cuando te vuelvas, acaso si te vuelves, en el centro sincero de lo humano-divino, con la custodia pura entre las manos, oficiando el ritual que condice y guarda a mi amor, ya trascendido por tu vida, en otro amor que me trasciende y salva en ti, definitivamente. 
2

VIERNES DE LA CRUZ

a Guillermo de la Cruz Coronado

Si, por cesación de fe,

porque todos negaron de $\mathrm{ti}$

y dejaron tu nombre

ser pasto de vilanos;

porque uno a uno

bajo el soplo del miedo

prevaricaron contra ti,

y ocultaron sus rostros

en tinieblas de dudas,

te has quedado solo:

-cordero en el erial-.

Única luz que salva!

pero que para escarnio

nuestro, sufres ocultación.

Si, ahora es el quebranto;

el chocar de las manos

reproduce tu tránsito

con el temblor de todo

lo que habita en la tierra;

porque entonces, sí,

porque sólo entonces

sentimos tu soledad;

la orfandad de Dios

adentro de nosotros,

y comprendemos también

para nuestra esperanza,

que aunque oculto

no nos abandonaste. 


\author{
Viernes de la Cruz, \\ El templo reproduce \\ el alma, uno a uno \\ tus bienamados \\ fueron dejándote \\ y dejándonos en soledad \\ y en sombras; pero tú \\ tienes, en tu ocultación, \\ la fuerza para hacer \\ en tres dias el acto \\ de erigir a tu templo; \\ y nosotros, rememorándote, \\ la esperanza sincera \\ de alcanzar tu gracia \\ para nuestra resurrección \\ y salvación, ahora \\ y para siempre, amén.
}

\title{
RONDÓ
}

\section{I}

Ella tendió su mano... (dentro de buenos aires otras manos quedaron suspendidas esperando el destino de su gesto)

Él la apretó mirándole los ojos. $\mathrm{Su}$ mirada de óleo lo miraba desde su inmovilidad de ojos castaños.

Estaba allí, y la pensó un paje obra de los colores de Velázquez. 
-Está en su casa-,

i $\mathrm{Su}$ voz era pequeña, otra voz no cabía en su menudo cuerpo.

El se encontró de pronto con su infancia del brazo y por la calle).

Ella tenía una sonrisa familiar.

El la miraba desde un presente antiguo

\section{II}

Ella tendió el mantel.

(En sus manos, hechas para peinar

rubios cabellos infantiles,

el pan cumplía su rito

$y$ el vino se ofrendaba).

Él alabó su casa.

(Como en la Última Cena

se comió pescado).

Los comensales bebían y danzaban

festejando sus intimas memorias.

Ella y Él se decían buenasnoches.

(Dentro de buenos aires,

la ciudad junto al río,

amanecía). 